\title{
MANAGERSKO IZOBRAŽEVANJE NA EKONOMSKI FAKULTETI V LJUBLJANI
}

$\mathrm{V}$ preteklosti gospodarstva $\mathrm{v}$ prehodu zaradi planske narave niso namenjala posebne pozornosti managerskemu izobraževanju. Slovensko (jugoslovansko) gospodarstvo je imelo pri tem $\mathrm{v}$ primerjavi $\mathrm{z}$ drugimi gospodarstvi $\mathrm{v}$ prehodu nekatere prednosti. Bilo je manj učinkovito od razvitih gospodarstev, vendar pa je bilo zaradi pomena trga in večje usmerjenosti navzven učinkovitejše od centralno-planskih gospodarstev. Managersko izobraževanje se je začelo v Sloveniji razvijati sredi šestdesetih let.

\section{VLOGA EKONOMSKE FAKULTETE V RAZVOJU MANAGERSIKEGA IZOBRAŽEVANJA}

Ekonomska fakulteta $\mathrm{v}$ Ljubljani ima kot akademska ustanova najdaljšo tradicijo v izobraževanju managerjev v Sloveniji. Začetki segajo v leto 1967, ko je začela, kot eden prvih institucionalnih organizatorjev in izvajalcev managerskega izobraževanja v Sloveniji, razvijati prve programe za tako imenovane potrebe gospodarske prakse, in sicer z organizacijskim in finančnim sodelovanjem GZS. Fakulteta podjetjem takrat ni mogla sama ponuditi programov, ker se tedaj direktorjem ni smelo ponujati kakršnih koli oblik znanja, ne da bi jih oblastne institucije preverile. Pod vodstvom prof. Ivana Turka, ki je bil pobudnik in dolga leta gonilna sila te dejavnosti, je fakulteta razvila dvo- in tritedenske in tudi krajše programe za vodilne iz gospodarstva in skrbela za njihovo izpopolnjevanje. Številne teme s takratnih seminarjev so podobne današnjim, na primer analiza trga in komercialne politike, delitev dohodka in motiviranje osebja, politika prodajnih cen, merila investiranja $\mathrm{v}$ podjetju, navezovanje poslovnih stikov s tujino. Do leta 1972 je bila seminarskopodjetniška dejavnost Ekonomske fakultete organizirana na Inštitutu za ekonomiko in or- ganizacijo podjetja $\mathrm{v}$ okviru raziskovalnega centra fakultete. Leta 1972 pa so na fakulteti ustanovili posebno organizacijsko enoto Izobraževalni center Ekonomske fakultete ICEF. V tem obdobju, na koncu 60 . let, je fakulteta, prav tako na pobudo prof. Ivana Turka, uvedla magistrski študij iz organizacije in vodenja podjetij, ki je bil prvi tovrstni študij v Sloveniji. Obe dodatni dejavnosti fakultete, seminarska dejavnost in podiplomski študij iz organizacije in vodenja podjetij, sta imeli enaka izhodišča. Prvič v tem, da se poslovno in organizacijsko znanje uveljavlja kot znanje, ki ni manj vredno od ekonomskega. Drugačno je zaradi drugačnih potreb tistih, ki so se zaposlovali v podjetjih. Seminarska dejavnost in nov podiplomski študij pa sta imela enaka izhodišča tudi v naravi jugoslovanskega gospodarstva, kjer je imel trg, domači in tuji, opazno vlogo. Managersko izobraževanje na Ekonomski fakulteti je sredi 70. let, $\mathrm{v}$ obdobju uvedbe integralnega planskega samoupravnega sistema, za deset let delno usahnilo. V tem obdobju je GZS ustanovila posebno šolo za izobraževanje poslovodnih delavcev v Škofji Loki. Šola je bila internatske narave. Iz te šole sta se čez nekaj let razvila Center za poslovodne delavce na Brdu pri Kranju in Center za zunanjetrgovinske delavce $\mathrm{v} \mathrm{Ra-}$ dencih. Za fakulteto so se pokazale boljše možnosti ob koncu 80. let, ko je začel ICEF množično izvajati programe za računovodske in finančne direktorje, podjetniško šolanje, študijske tečaje in številne kratke oblike izobraževanja poslovodnih delavcev. ICEF se je leta 1990 preimenoval v CISEF.

Od začetka 90. let priredi CISEF vsako leto več kot 100 seminarjev in drugih krajših oblik izpopolnjevanja $\mathrm{v}$ zvezi s financami in bančništvom, trženjem, organizacijo, strateškim managementom, ekonomiko, računovodstvom, ravnanjem s človeškimi viri in tujimi jeziki. Vsako leto prihaja več kot 2500 
udeležencev, največ iz bank, zavarovalnic in industrije. Udeleženci so večinoma diplomanti Ekonomske fakultete in zasedajo pomembne položaje ter položaje $\mathrm{v}$ srednjem managementu. V seminarje je vključenih več kot 100 predavateljev, z Ekonomske fakultete in z obeh slovenskih univerz ter priznanih strokovnjakov, uspešnih managerjev, ki so zaposleni v bankah, inštitutih, podjetjih ter vladnih in drugih službah; čedalje več je tudi predavateljev iz tujine. CISEF je tržno usmerjena ustanova in letno ustvari več kot en milijon DEM prihodka. Organizacijo celotne izobraževalno-svetovalne dejavnosti ob pomoči strokovnih služb na Ekonomski fakulteti vodijo štirje redno zaposleni delavci.

CISEF - Center za strokovno izpopolnjevanje in svetovalno dejavnost Ekonomske fakultete je $v$ teh letih postal največji univerzitetni poslovno-izobraževalni center v Sloveniji. Njegovo poslanstvo bi lahko strnili v treh postavkah: 1. zadovoljiti potrebe diplomantov Ekonomske fakultete in drugih poslovodnih delavcev po izpopolnjevanju ekonomskega, poslovnega in organizacijskega znanja, 2 . povezati fakulteto (kot institucijo in fakultetne učitelje) z gospodarstvom in 3 . ustvarjati dodatna finančna sredstva za potrebe fakultete.

CISEF želi tudi $\mathrm{v}$ prihodnje ostati $\mathrm{v}$ zavesti udeležencev in drugih javnosti kot univerzitetni izobraževalni center, kot mesto vračanja diplomantov na Ekonomsko fakulteto in kot prostor za strokovna srečanja in razprave. Poseben izziv za CISEF je zadovoljevanje izobraževalnih potreb najvišjega managementa, ki mu namenja precejšnjo pozornost. Pri tem bo treba še bolj izrabiti prednosti, ki jih ponuja fakulteta, in strniti dosežke na raziskovalnem področju ter jih povezati z drugimi oblikami podiplomskega izobraževanja. Prav magistrski in doktorski študij bi morala postati inkubator za razvoj novega znanja o delovanju gospodarstva in managementa, ki bi ga bilo mogoče prenašati na vsa področja delovanja Ekonomske fakultete. Sodelovanje domačih predavateljev in raziskovalcev s priznanimi tujimi predavatelji in raziskovalci ter $\mathrm{z}$ uspešnimi managerji slovenskih in tujih podjetij - nekaj spodbudnih izkušenj na rednem podiplomskem študiju Ekonomske fakultete že imamo - je lahko primerno izhodišče za oblikovanje znanja, ki bi ga CISEF ponudil za zadovoljitev izobraževalnih potreb tega najvišjega segmenta odjemal- cev. To seveda ne bo lahko, saj je trg izobraževalnih managerskih storitev $\mathrm{v}$ Sloveniji zelo konkurenčen in ponudba managerskega izobraževanja pogosto presega povpraševanje po njem. Pot do uspeha v prihodnje vidi CISEF v upoštevanju in stalnem preučevanju potreb odjemalcev izobraževalnih storitev, to je sedanjih in morebitnih udeležencev, $v$ vzdrževanju in razvijanju dolgoročnih odnosov $\mathrm{z}$ njimi, $\mathrm{v}$ kakovosti storitev in strokovni odličnosti na vseh ravneh.

\section{SKLEP}

Po 25 letih se razmerje med ponudniki znanja in njegovimi naročniki spreminja. Ekonomska fakulteta ni več le »učitelj «, gospodarstvo pa ni več »učenec «. Novo kakovost v odnosih bi lahko imenovali partnerstvo, pri katerem gre za vzajemno učenje, vzajemne interese, vzajemno tveganje in odgovornost. Slovensko gospodarstvo potrebuje sodobno znanje $\mathrm{v}$ zvezi z ekonomijo, organizacijo in poslovnimi vedami, fakulteta pa je $\mathrm{v}$ stikih $\mathrm{z}$ direktorji in strokovnimi delavci bogatejša zaradi dragocenih izkušenj, ki jih imajo udeleženci seminarjev. Prepričani smo, da se učenju kot permanentnemu življenjskemu procesu ne bo izognil nihče, ki bo hotel preživeti in se razvijati.

Marijana Jazbec CISEF v Ljubljani

\section{VIRI}

Jazbec, M., Prašnikar, J., Rovan, J. Izobraževanje managementa v Sloveniji, Analiza odjemalcev izobraževalnih storitev CISEF, Ekonomska fakulteta, 1996.

Jurančič, I. Nastanek, razvoj in izvajanje izobraževalnega programa v šoli za poslovodne kadre v Škofji Loki, Organizacija in kadri, št. 11, 1979, str. 599-604.

Možina, S. Izobraževalna dejavnost za kadre v gospodarstvu, s katero se je ukvarjala EF od. 8. 3. 1946 do 30. 9. 1976, almanah ob 30. letnici EF, Ljubljana, 1976.

Pogačnik, B., Žužek, I. Dopolnilno izobraževanje pri nas - gonilo ali zavora razvoja? Gospodarski vestnik, št. 7, februar, 1986, str. 14-16.

Prašnikar J., Svejnar J. Economic Behavior of Yugoslav Enterprises, Advanced in the Economic Analysis of Participatory and Labor Managed Firms, JAI Press Inc., Vol 3, 1988, 237-311.

Ribnikar, I. Prispevek o CISEF ob 50. letnici Ekonomske fakultete, Ljubljana, 1996

Tomat, V.: Program in režim izobraževanja poslovodnih kadrov v Škofji Loki, Organizacija in kadri, št. 11, 1978, str. 605-608.

Turk, I. Delovanje Izobraževalnega centra Ekonomske fakultete od 1.10. 1976 do 30. 9. 1986, almanah ob 40. letnici EF, Ljubljana, 1986. 